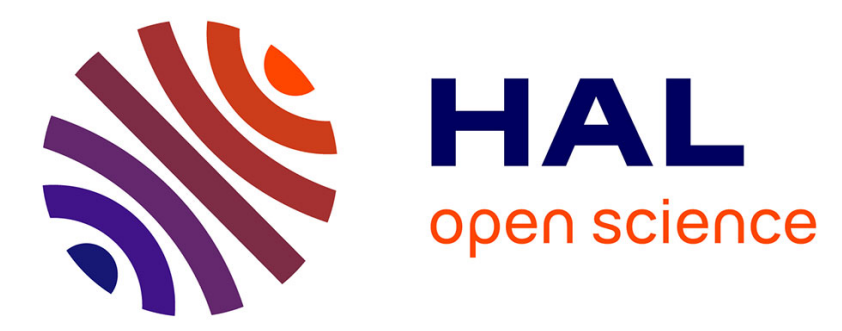

\title{
Experimental investigation of the effect of moisture on the acoustic properties of lightweight substrates used in green envelopes
}

Emmanuel Attal, Yorick Buot de L'Epine, Nicolas Dauchez, Bertrand Dubus

\section{- To cite this version:}

Emmanuel Attal, Yorick Buot de L'Epine, Nicolas Dauchez, Bertrand Dubus. Experimental investigation of the effect of moisture on the acoustic properties of lightweight substrates used in green envelopes. Applied Acoustics, 2021, 180, pp.108108 (12). 10.1016/j.apacoust.2021.108108 . hal03309599v2

\section{HAL Id: hal-03309599 \\ https://hal.science/hal-03309599v2}

Submitted on 30 Jul 2021

HAL is a multi-disciplinary open access archive for the deposit and dissemination of scientific research documents, whether they are published or not. The documents may come from teaching and research institutions in France or abroad, or from public or private research centers.
L'archive ouverte pluridisciplinaire HAL, est destinée au dépôt et à la diffusion de documents scientifiques de niveau recherche, publiés ou non, émanant des établissements d'enseignement et de recherche français ou étrangers, des laboratoires publics ou privés. 


\title{
Experimental investigation of the effect of moisture on the acoustic properties of lightweight substrates used in green envelopes
}

\author{
Emmanuel Attal ${ }^{\mathrm{a}, \mathrm{b}, *}$, Yorick Buot de l'Epine ${ }^{\mathrm{c}}$, Nicolas Dauchez ${ }^{\mathrm{c}}$, Bertrand \\ Dubus $^{\mathrm{b}}$ \\ ${ }^{a}$ Institut FEMTO-ST, CNRS, Université de Bourgogne Franche-Comté, Besançon, France. \\ ${ }^{b}$ Univ Lille, CNRS, Ecole Centrale, Yncréa, Univ Valenciennes, IEMN, UMR 8520 \\ 59046 Lille cedex, France. \\ ${ }^{c}$ Univ de Technologie de Compiègne, Laboratoire Roberval UMR 7337, BP 20529, 60205, \\ Compiègne Cedex, France.
}

\begin{abstract}
Substrates are used in green walls and roofs to supply air and water to the roots of the growing plants. These substrates are porous with micropores which store water and macropores which facilitate drainage and air entry. Effect of moisture on acoustic absorption is studied for two lightweight substrates: coir dust and perlite. Measurement of dry and moistened substrates are conducted to evaluate their effective speed of sound, attenuation, characteristic impedance, compressibility and density between $100 \mathrm{~Hz}$ and $1000 \mathrm{~Hz}$ using an impedance tube and the three microphone-two load method. Effect of moisture on these quantities is found to depend strongly upon the interaction between water and substrate particles at the microscale. Performance of rigid-frame and limp frame porous models is evaluated when applied to the characterization of dry and moistened lightweight substrates. Finally, sound absorption of substrate layers and composite plant-substrate samples is analyzed for different moisture contents.

Keywords: sound absorption, lightweight substrate, acoustic porous medium, moisture, green envelope
\end{abstract}

\footnotetext{
${ }^{*}$ Corresponding author

Email address: emmanuel.attal@hotmail.fr (Emmanuel Attal)
}

Preprint submitted to Journal of ${ }^{A} T_{E} X$ Templates

March 9, 2021 


\section{Introduction}

4

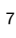

For several decades, growing environmental concern in urban areas has stimulated the development of green building envelopes with significant benefits on stormwater management 1, wildlife habitat [1, energy conservation 1, 2, air quality [1, 3], mitigation of urban heat island effect [1, and noise reduction [4. In the latter case, in-situ measurements demonstrated that the main improvement comes from the increased absorption of sound when highly reflecting building materials are covered by green roofs [5, 6] and green walls [4]. Numerical simulations were also conducted to evaluate how propagation of traffic noise was affected by building enveloppe greening for different urban configurations [7, 8. Laboratory experiments have shown that the main contribution of this absorption comes from the substrate with a clear dependence to substrate composition [5, 9, 10, 11, geometry [5, 11, 12, 13] and moisture content [5, 9, 12 .

Substrates are porous materials containing both gas and liquid in order to supply water and air to the roots and achieve growth of plants. Water availability depends upon substrate composition and volume but varies also with plant development and external environmental conditions [14. The effect of moisture or water content on the acoustic properties of soils (sandstones, clay...) such as airflow resistivity [15, ground impedance [16, 17, 18] speed of sound [19] and attenuation [19] has been widely studied. Long-term in-situ experimentations were also conducted on green roofs incorporating relatively heavy substrates to evaluate the variation of acoustic signal attenuation with substrate water content. Van Renterghem and Bottledooren reported variations reaching $10 \mathrm{~dB}$ between dry substrate and moistened substrate close to saturation in the 250-1250 $\mathrm{Hz}$ frequency range 20. Liu and Hornikx performed similar experiments for two roofs incorporating different substrates [21]. Correlation between change in acoustic wave attenuation and substrate water content was observed for one roof and not for the other one. The fact that the porosity of the substrate was weakly dependent of water content was suggested to explain the absence of change for 
the latter case. Connelly and Hodgson [5] evaluated the absorption coefficient at normal incidence of nine different (heavy) substrates in an impedance tube at three levels of volumetric water content: oven-dry, wilting capacity and field capacity. They also observed a decrease of absorption coefficient with moisture content.

Some recent works have also addressed the effect of moisture on low density substrates which are preferred for green walls to reduce total weight. Horoshenkov et al 9 measured in an impedance tube, the absorption coefficient at normal incidence of two dry and moistened substrates: a clay soil and a light substratum made of coir, perlite and polymer gel. In the 100-1500 Hz frequency range, absorption coefficient of clay soil dropped from 0.2-0.7 to 0.1-0.12 for a relatively small amount of added water. For the light substratum, a much smaller decrease was observed from 0.8-0.9 to 0.6-0.75 at a larger moisture content and only above $300 \mathrm{~Hz}$. Different porous models were used for clay soil and substratum in order to evaluate the variation of model parameters under moisture condition. Yang et al 12 measured the absorption coefficient of heavy (topsoil) and light (mixture of coir, perlite and water-retaining polymer) substrate layers for different moisture contents. Average absorption coefficient was obtained in reverberant room for topsoil while absorption coefficient at normal incidence was measured in impedance tube for the mixture. For all frequencies between 100 and $4000 \mathrm{~Hz}$, absorption coefficient of topsoil was found to decrease significantly with increasing moisture while those of the light substrate was increasing slightly. The purpose of this work is to analyze how moisture affects the effective acoustic properties of two different lightweight substrates and to evaluate the consequences of these property changes on the acoustic absorption of substrate and plant-substrate samples. Measurement of substrate effective properties is carried out in an impedance tube using the three microphone-two loads method. The measurement method, which also provides sample absorption coefficient and surface impedance, as well as the considered lightweight substrates, the preparation of the samples and their physical characterization are described in section 2, Measured physical and effective acoustic properties 
of the three substrates, dry and moistened, are analyzed in section 3 . Performance of rigid-frame and limp frame of porous models is considered in section 4 when applied to the characterization of dry and moistened lightweight substrates. The variation of normal incidence absorption coefficient with moisture contents discussed in section 4 for substrate single layers and in section 5 for composite plant-substrate samples.

\section{Experimental procedure}

\subsection{Measurement method}

Acoustic characterization of substrate samples is performed in an impedance tube (Fig 1) using the three-microphone two-load method [22]. A specific tube of large diameter $(192 \mathrm{~mm})$ is used to have a sample diameter significantly larger than the size of sample constituents (substrate particles, leaves).

Four loudspeakers (type Visaton FRS) are mounted in the PVC front disk located at the front end of the tube. A movable Teflon piston is positionned at the other end. A plastic sample holder contains the substrate maintained by two pieces of textile net. Acoustic pressure measurements are performed with three microphones (Sennheiser MKE 2P with $3.8 \mathrm{~mm}$ diameter). Two microphones are located in front of the sample respectively at 80 and $90 \mathrm{~cm}$ from the front end of the tube. The third microphone is located at the center of the movable piston behind the sample. The sound card (RME-Fireface 802) control inputs and outputs of the system. The excitation signal is a step by step sine. More details on experimental set-up may be found in reference [11

Sample transfer matrix parameters are measured in the $100-1000 \mathrm{~Hz}$ frequency range. Assuming $e^{+j \omega t}$ time dependency where $\omega$ is the circular frequency and the time, sample transfer matrix $T(\omega)$ relating acoustic pressures $\mathrm{P}$ and velocities $V$ at $x=0$ and $x=d$ is written as

$$
\left[\begin{array}{l}
P(0) \\
V(0)
\end{array}\right]=\left[\begin{array}{ll}
T_{11}(\omega) & T_{12}(\omega) \\
T_{21}(\omega) & T_{22}(\omega)
\end{array}\right]\left[\begin{array}{l}
P(d) \\
V(d)
\end{array}\right],
$$


In the three-microphone two-load method, the transfer matrix is evaluated

89 by using the three measured transfer functions between the microphones for

90 two different sizes of the backing cavity [22]. Assuming that the sample may be

91 described as an ideal homogeneous fluid medium, the transfer matrix is written

92 as

$$
\left[\begin{array}{cc}
T_{11}(\omega) & T_{12}(\omega) \\
T_{21}(\omega) & T_{22}(\omega)
\end{array}\right]=\left[\begin{array}{cc}
\cos (k(\omega) d) & j Z_{c}(\omega) \sin (k(\omega) d) \\
\frac{j \sin (k(\omega) d)}{Z_{c}(\omega)} & \cos (k(\omega) d)
\end{array}\right],
$$

93

94

95

95 sample. $k, Z_{c}$ and $c$ are deduced from the transfer measured matrix using

$$
\begin{gathered}
k(\omega)=\frac{\arccos \left(T_{11}(\omega)\right)}{d}, \\
c(\omega)=\frac{\omega}{k(\omega)}, \\
Z_{c}(\omega)=\sqrt{\frac{T_{12}(\omega)}{T_{21}(\omega)}} .
\end{gathered}
$$

96 As homogeneous samples are symmetric, $T_{11}$ and $T_{22}$ are equal in an homo-

${ }_{97}$ geneous sample. Therefore, measured values of $T_{11}$ and $T_{22}$ may be compared

98 to strengthen the hypothesis of homogeneity:

$$
T_{11}(\omega) \approx T_{22}(\omega)
$$

99 $\quad$ Effective compressibility $\chi$ and density $\rho$ are obtained using

$$
\begin{gathered}
\chi(\omega)=\frac{1}{c(\omega) Z_{c}(\omega)}, \\
\rho(\omega)=\frac{Z_{c}(\omega)}{c(\omega)} .
\end{gathered}
$$


Finally, the absorption coefficient $\alpha$ and the specific impedance $Z_{s}$ of the sample in rigid backing condition are obtained using

$$
\begin{gathered}
\alpha(\omega)=1-\left|\frac{T_{11}(\omega)-Z_{0} T_{21}(\omega)}{T_{11}(\omega)+Z_{0} T_{21}(\omega)}\right|^{2}, \\
Z_{s}(\omega)=\frac{T_{11}(\omega)}{T_{21}(\omega)},
\end{gathered}
$$

where $Z_{0}$ is the characteristic impedance of air. More details on experimental set-up and measurement method may be found in reference [1]

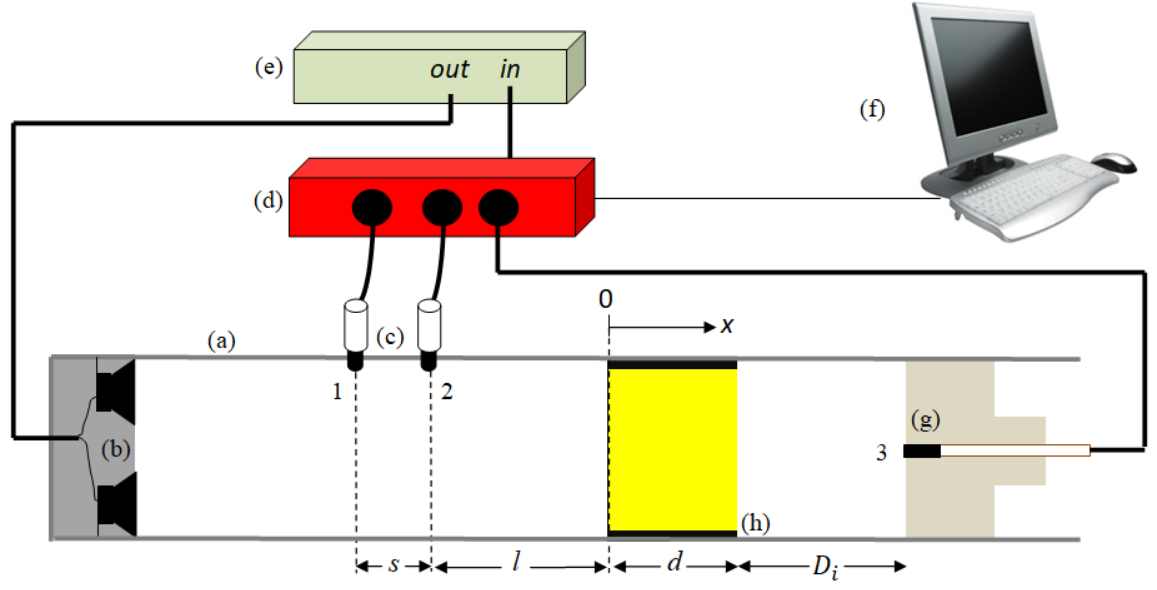

Figure 1: Schematic view of the experimental setup: (a) stainless steel tube; (b) cylindrical PVC disk integrating 4 loudspeakers; (c) microphones; (d) sound card; (e) amplifier; (f) computer; (g) flush mounted microphone on movable piston; (h) sample holder containing the sample.

\subsection{Samples description, preparation and physical characterization}

High content of available water and adequate air supply are considered as the most important physical characteristics required for substrates in order to achieve optimal growth of plants. All substrates are composed of three phases: solid, aqueous and gaseous. The capacity of a substrate to store water and air and its ability to provide them to the plant are determined by its porosity characteristics [23, 24]. Water is mainly held by the micropore space of the 


\begin{tabular}{|c|c|c|c|c|}
\cline { 2 - 5 } \multicolumn{1}{c|}{} & Bulk density $($ dry $)\left(\mathrm{kg} \cdot \mathrm{m}^{-3}\right)$ & Effective porosity (\%) & Total water holding capacity (\%) & Reference \\
\hline \multirow{4}{*}{ Coir dust } & $40-80$ & $85-89$ & $73-80$ & 25 \\
\cline { 2 - 5 } & $25-89$ & $98-94$ & $14-78$ & $26]$ \\
\hline \multirow{3}{*}{ Perlite } & 60 & 91 & 64 & 27 \\
\cline { 2 - 5 } & 140 & 70 & 25 & {$[27]$} \\
\hline
\end{tabular}

Table 1: Properties of coir dust and perlite substrates

substrate, while rapid drainage and air entry is facilitated by the macropores [25]. Therefore, an adequate distribution of large and small pores is essential for a good medium.

Two different substrates having low bulk density, high water holding capacity and low suction are considered in this work: coir dust and perlite. Their microporosity corresponds to the internal porosity of their constituent particules and the macroporosity to the inter-particle porosity. Their main properties found in the literature are given in table 2 . The bulk density of the substrate is defined as its dry mass per unit of volume. The effective porosity is the ratio of the total volume of open pores to the total volume of the substrate. It can be determined using a porosimeter. The storage of water in a growth substrate is described by the water retention curve which relates volumetric water content to water suction 23,24 . Container capacity is reached in the substrate when water stops draining following saturation. It is usually defined at a suction of 1 $\mathrm{kPa}$. The total water holding capacity is the ratio of the total volume of water held in substrate at container capacity to the total volume of substrate. As Young-Lapace equation states that capillary pressure is inversely proportional to channel radius, it is usually admitted that water retention curve is essentially the pore-size distribution curve [23].

Coir dust (Fig 2 (a)) is a residual waste of coir processing. The main part of coir dust is constituted by pithy tissue particles sizing between 1 and $4 \mathrm{~mm}$ for more than $90 \%$ of the particles 29 . Pithy tissue particles have an internal porosity of approximately $40 \%$ and exhibit round-shaped external pores (average diameter of $40 \mu \mathrm{m})$ accounting for a relative surface porosity of about $40 \%$ 


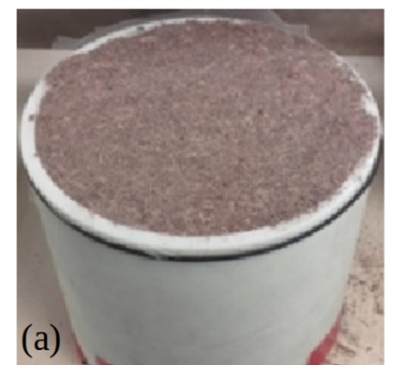
of micropores.

(Fig 3 (a)). Internal and surface porosities are interconnected. The high water storage capacity of coir dust is associated to high surface porosity and larger openings in coarse pithy tissue which facilitate the water penetration into the cells [28. Remaining particles of larger size are short coir fibers. Coir dust properties differ significantly between sources (table 1 ). This variation is closely related to the particle size distribution [30, substrates with smaller particles exhibiting higher bulk density, smaller effective porosity and a larger proportion

Perlite is an amorphous aluminum silicate glassy volcanic rock which traps crystalline water into its mass. When heated above $900^{\circ} \mathrm{C}$, entrapped water molecules turn to steam. Perlite expands up to 4-20 times of its original volume and become porous [31. Expanded perlite (Fig,2(b)) is composed of millimetersize particles having a crystal-like porous and glassy structure with countless number of pores sizing from 20 to $100 \mu \mathrm{m}$ (Fig. 3(b)) [28, 32]. Properties of expanded perlite substrates also vary with particle size distribution [27, 28, 33. Compared to coir dust substrates, expanded perlite substrates tend to have higher bulk density, lower effective porosity and lower total water holding capacity. Expanded perlite is used in hydroponics and green systems alone as a medium or as a soil amendment to retain moisture and lighten compact soils.

Figure 2: (a) Coir dust; (b) Perlite; (c) Japanese spindle.
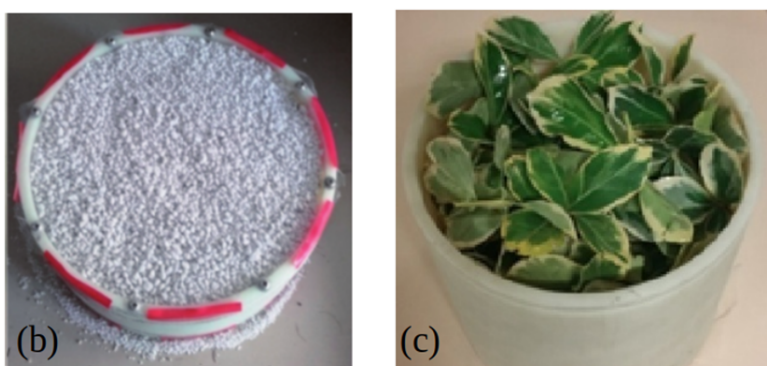

Each substrate is dried in an oven at $130^{\circ} \mathrm{C}$ during 15 hours and then mixed with a controlled amount of water. Moisture content is defined as the ratio of the mass of added water to the mass of the dry substrate. Substrate and water 

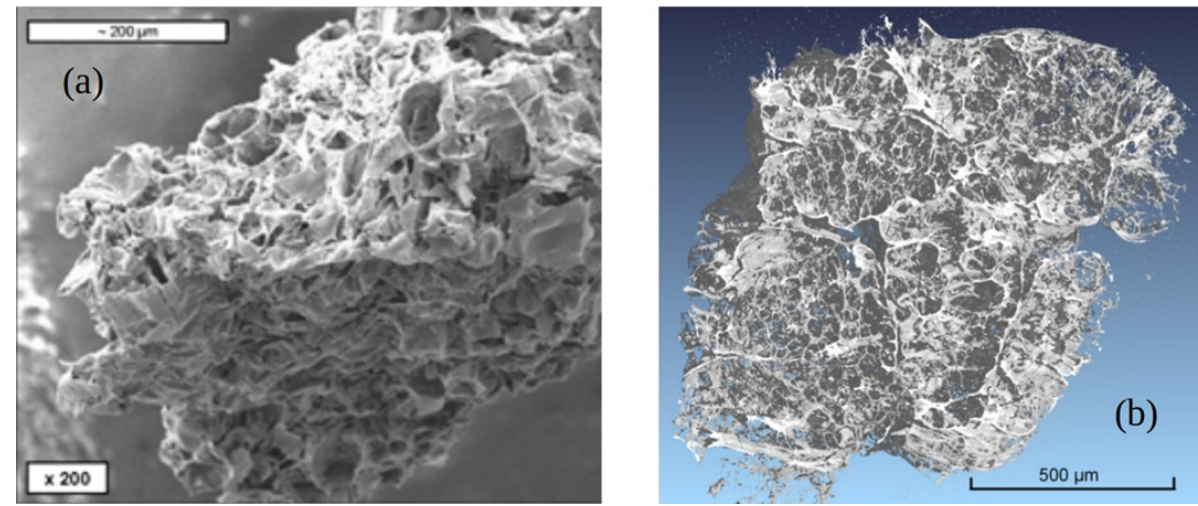

Figure 3: (a) Coir dust pithy tissue particle (image by scanning electron microscopy) from 29]; (b) microstructure of an expanded perlite particle (pseudo-image by computer micrography) from 32 .

are mixed mechanically in order to homogeneize the distribution of water.

The dry or wet substrate is then placed in the $8 \mathrm{~cm}$ thick sample holder as evenly as possible and without compaction. Textile nets are stretched on the top and bottom ends of the sample holder to maintain the soil-air interfaces perpendicular to tube axis 17. Acoustic measurements are made on four different substrate samples for each moisture content.

Additional characterizations of dry and wet substrates properties are also conducted. Density, effective porosity and airflow resistivity are directly measured using an electronic balance, a porosimeter and a resistivimeter. An inverse method is also used to determine the parameters of the porous model (porosity, airflow resistivity, tortuosity, viscous and thermal lengths) from absorption curves measured in an impedance tube. It relies on the minimization of a least square cost function between measurements and simulation with a Johnson Allard-Champoux [34, 35] or limp [36] porous models.

The plant considered in this work is Japanese spindle (Euonymus japonicus), a small shrub with oval leaves which are about $5 \mathrm{~cm}$ long and $3 \mathrm{~cm}$ wide (Fig. 2(c)). Plant samples have an air-filled porosity of $95 \%$ which is evaluated by dividing the total volume of the plant by the internal volume of the sample 
holder. The volume of the plant is obtained by submerging branches and leaves in a graduated cylinder filled with water and measuring the water level variation. Plant samples are constituted by a set of small branches introduced in the sample holder. The foliage is disposed in the whole volume of the sample holder to obtain the most homogeneous distribution possible. Textile nets are added on the top and bottom of the sample holder to keep the air/plants interface perpendicular to tube axis and serve as reference surfaces.

\section{Measurement of dry and wet substrates}

\subsection{Physical properties of substrates}

Measurement are performed on three different samples for each substrate and each moiture content. Average value and standard deviation of measured porosity $\phi$, density $\rho$ and airflow resistivity $\sigma$ are reported in table 2 for perlite and coir dust at different moisture contents $\tau$. As airflow resistivity of coir dust with $15 \%$ moisture content was found to be highly sensitive to the substrate-water mixing process, results are reported for three different processes. Variations of these quantities (normalized to their value at dry state) with respect moisture content are displayed in Fig,4. Simulated variations of these quantities assuming a constant volume of the substrate are also reported. If the decrease of porosity is due to the added volume of water, the theoretical porosity of the wet substrate is written as

$$
\phi_{\text {wet }}=\phi_{d r y}-\tau \frac{\rho_{\text {dry }}}{\rho_{\text {water }}},
$$

If the increase of density is due to the added mass of water, the theoretical density of the wet substrate is

$$
\rho_{w e t}=\rho_{d r y}(1+\tau)
$$

For perlite, the decrease of porosity is larger than expected from Eq.11. A possible mechanism would be the trapping of water at the surface of perlite 
particles that could obstruct the micropores of the particule without occupying their entire volume. The increase of measured density is correctly described by Eq. (12) confirming that the volume of perlite substrate remains constant when it is moistened. Measured airflow resistivity of perlite substrate is found to decrease with moisture content contrary to previous mesurements on sand showing an opposite effect [15, 17]

For coir dust, measured variations depend strongly upon considered moisture content range. For moisture content between 0 and $15 \%$, variations of porosity and density are correctly described by Eqs. 111 and (12). Airflow resistivity rises by 28 to $124 \%$ with high sensitivity to substrate-water mixing process. For moisture contents between 15 and $65 \%$, porosity and density stay relatively constant despite the additional volume and mass of water brought to the substrate. This effect can be explained by the penetration of water in pithy tissue cells [29] which produces an increase of their volume and also of volume of the whole sample. This observation is also consistent with the continuous decrease of airflow resistivity as the pore size is assumed to increase when particle size increases. It is possible that water also penetrates in pithy tissue cells at moisture between 0 and $15 \%$ with a different macroscopic effect. Initially, expansion of pithy tissue particles could tend to diminish pore size before reaching an equilibrium through contact forces with neighboring particles. When moisture content keeps increasing, particles tend to expand and contact forces generate an internal pressure and therefore an increase of sample volume. For a $200 \%$ moisture content close to saturation, direction of variations predicted by Eqs. 111 and (12) are recovered as porosity decreases and density increases. Further decrease of airflow resistivity is also observed.

\subsection{Effective acoustic properties of substrates}

Measurement of acoustic properties are performed on four different samples for each substrate and each moiture content. Average value and standard deviation are reported on Figure 5 to 8. Symmetry of the sample is also verified 


\begin{tabular}{|c|c|c|c|c|c|c|c|}
\hline Substrate & $\begin{array}{l}\text { Moisture } \\
\text { content }\end{array}$ & $\begin{array}{l}\text { Porosity } \\
\text { average }\end{array}$ & $\begin{array}{c}\text { Porosity standard } \\
\text { deviation (\%) }\end{array}$ & $\begin{array}{c}\text { Density average } \\
\quad\left(\mathrm{kg} \cdot \mathrm{m}^{-3}\right)\end{array}$ & $\begin{array}{c}\text { Density standard } \\
\text { deviation (\%) }\end{array}$ & $\begin{array}{c}\text { Airflow resistivity } \\
\text { average } \\
\left(\mathrm{Ns.m}^{-4}\right)\end{array}$ & $\begin{array}{c}\text { Airflow resistivity } \\
\text { standard deviation } \\
(\%)\end{array}$ \\
\hline \multirow{3}{*}{ Perlite } & 0 & 0,773 & 1,7 & 290,1 & 7,6 & 3562 & 11,1 \\
\hline & 0,15 & 0,710 & 0,6 & 334,2 & 2,9 & 2663 & 8,1 \\
\hline & 0,30 & 0,651 & 3,1 & 398,1 & 1,5 & 2038 & 4,5 \\
\hline \multirow{7}{*}{ Coir dust } & 0 & 0,920 & 0,2 & 133,6 & 2,3 & 39615 & 5,2 \\
\hline & \multirow{3}{*}{0,15} & \multirow{3}{*}{0,899} & \multirow{3}{*}{0,7} & \multirow{3}{*}{152,5} & \multirow{3}{*}{4,1} & 50879 & 13,8 \\
\hline & & & & & & 67343 & 13,3 \\
\hline & & & & & & 88948 & 0,6 \\
\hline & 0,30 & 0,900 & 0,2 & 148,2 & 0,6 & 46647 & 11,2 \\
\hline & 0,65 & 0,886 & 1 & 147,6 & 0,6 & 25261 & 4,4 \\
\hline & 2,00 & 0,804 & 1,3 & 234,8 & 7 & 13209 & 8,6 \\
\hline
\end{tabular}

Table 2: Porosity, density and airflow resistivity of coir dust and perlite substrates measured at different moisture contents

by comparing measured values of $T_{11}$ and $T_{22}$. As measured $T_{11}$ and $T_{22}$ are different above $500 \mathrm{~Hz}$ for coir dust sample at $15 \%$ and $30 \%$ moisture content effective properties are not evaluated at these frequencies and water contents.

Measured spectra of effective speed of sound, attenuation, characteristic impedance, compressibility and density are reported in Figs. 5 to 8 for dry and moistened coir dust and perlite substrates between 100 and $1000 \mathrm{~Hz}$. Frequency spectra of the real and imaginary parts of the effective speed of sound (Fig. 5) show that both substrates, wet or moistened, are dispersive. For dry substrates, effective speed of sound is lower than speed of sound of air and effective attenuation (Fig. 6) is higher than attenuation in air, the lower the speed of sound, the higher the attenuation. For frequencies varying between 100 and $1000 \mathrm{~Hz}$, speed of sound and attenuation ranges measured on dry substrates are respectively $60-100 \mathrm{~m} . \mathrm{s}^{-1}$ and $4-30 \mathrm{~m}^{-1}$ for coir dust, $70-135 \mathrm{~m} . \mathrm{s}^{-1}$ and $4-14$ $\mathrm{m}^{-1}$ for perlite. Different changes of effective properties with moisture content are observed depending on the considered substrate. In coir dust with 15 and $30 \%$ moisture contents, speed of sound drastically decreases to $40-60 \mathrm{~m} . \mathrm{s}^{-1}$ and attenuation strongly increases to $7-30 \mathrm{~m}^{-1}$. Only very small change of these properties are observed when moisture content is increased from $15 \%$ and $30 \%$. For a moisture content of $200 \%$, real part of speed of sound and attenuation spectra are very close to those of dry coir dust. Imaginary part undergoes large 
oscillations with peaks at 270, 600 and $900 \mathrm{~Hz}$

Real part of effective characteristic impedance (Fig. 6) is also frequencydependent and decreases with frequency for both substrates. Characteristic impedance of dry perlite, 1000-2000 Pa $s \mathrm{~m}^{-1}$, and dry coir dust, 1000-2500 $P a s m^{-1}$ are much larger than air characteristic impedance. Different variations with moisture content are observed according to the substrate. Compared to the dry case, characteristic impedance of perlite decreases for all frequencies with a $15 \%$ moisture content and then barely changes when increasing moisture content to $30 \%$. For moistened coir dust, effective characteristic impedance increases continuously with moisture content from 15 to $200 \%$.

Real and imaginary parts of effective compressibility and effective density are displayed in Fig 7 and 8 respectively. For perlite, main changes with moisture are found for the real and imaginary parts of effective density which decreases by 25 to $50 \%$ in the whole frequency range. Real part of compressibility is barely modified for a $15 \%$ moisture content but decreases by 7 to $30 \%$ for a $30 \%$ moisture content. Coir dust exhibits a different behaviour under moisture conditions: for 15 or $30 \%$ moisture contents, the increase of real and imaginary parts of effective density reaches $100 \%$ between 200 and $400 \mathrm{~Hz}$ and progressively diminishes at higher frequencies. For a $200 \%$ moisture content, a smaller increase of the real part of effective density is observed at low frequency. Changes of compressibility depend both on moisture level and frequency. The decrease of the real part of effective compressibility is more pronounced near complete saturation while a larger increase of the magnitude of the imaginary part is obtained in the case of lower moisture contents.

\subsection{Acoustic properties of substrate samples in rigid backing condition}

Two independent measurements of the acoustic absorption by dry and wet substrate samples are presented. The first one is based on transfer matrix measurements using the three microphone-two loads method and calculation of absorption coefficient and surface impedance using equations 9 and 10 The second one is carried out with a commercial impedance tube (diameter 100 
$\mathrm{mm}$ ) according to the International Standard ISO 10534-2 [37]. Measurements are performed on substrates of the same origin and with the same preparation process. However, they are made with different samples because experimental set-ups are in different locations.

Absorption coefficient (measured with both methods) and surface impedance (measured with first method) are displayed in Fig 9 for $8 \mathrm{~cm}$ thick substrate samples in rigid backing conditions.

For dry coir dust samples, absorption coefficient is found to be almost constant above $200 \mathrm{~Hz}$, between 0.5 and 0.7 , for both measurement methods (Figs. $9(\mathrm{a})$ and $9(\mathrm{~b})$. In the presence of moisture, only small variations of absorption coefficient are observed with the first measurement method while the second one shows an absorption peak appearing progressively between 400 and $600 \mathrm{~Hz}$ with increasing moisture content. Attenuation remains high in the presence of moisture. Thickness resonances do not build up and a large mismatch is found between air characteristic impedance and the surface impedance of the sample that remain almost constant in the whole frequency range (Fig. 9(c)] .

For dry perlite, a peak appears in the absorption spectrum near $450 \mathrm{~Hz}$ with an absorption coefficient approximately equal to 0.9 for the first method (Fig 9(d) and near $650 \mathrm{~Hz}$ with an absorption coefficient close to 1 for the second method (Fig $9(\mathrm{e})$. In moistened perlite, this peak shifts up in frequency due to the increase of speed of sound. It may be noted that acoustic absorption remains close to 1 at resonance although attenuation drops in moistened perlite (Fig 6(c)). This result is explained by the improved matching of surface impedance with air characteristic impedance near resonance (Fig $9(\mathrm{f})$ which is related to the decrease of the characteristic impedance in the presence of moisture (Fig.6(d)). It may noted that radial effects could appear in the samples for the considered frequency range due to the low speed of sound in perlite and coir dust. Absorption coefficients measured by both methods could therefore differ because samples of different diameters are used [38. 


\section{Applicability of porous model}

In this section, the performance of two models of porous media, rigid-frame Johnson-Champoux-Allard model [34, 35, and limp frame model 36, is considered when applied to the characterization of dry and moistened coir dust and perlite substrates.

In the rigid-frame model, effective density and compressibility are written as

$$
\begin{gathered}
\rho_{\text {rigid }}(\omega)=\frac{\alpha_{\infty} \rho_{0}}{\phi}\left[1-j \frac{\sigma \phi}{\omega \alpha_{\infty} \rho_{0}} \sqrt{1+j \frac{4 \alpha_{\infty}^{2} \eta \rho_{0} \omega}{\sigma^{2} \Lambda^{2} \phi^{2}}}\right], \\
\chi(\omega)=\frac{\gamma-(\gamma-1)\left[1-j \frac{8 \kappa}{\omega \rho_{0} C_{p} \Lambda^{\prime 2}} \sqrt{\left.1+j \frac{\omega \rho_{0} C_{p} \Lambda^{\prime 2}}{16 \kappa}\right]^{-1}}\right.}{\frac{\gamma P_{0}}{\phi}},
\end{gathered}
$$

where $\gamma$ is the heat capacity ratio, $\rho_{0}, \eta, C_{p}$ and $\kappa$ are the density, the dynamic viscosity, the heat capacity and the heat conductivity of air, $P_{0}$ is the static pressure, $\phi, \alpha_{\infty}$ and $\sigma$ are the open porosity, the high frequency limit of the tortuosity and the static air flow resistivity of the substrate, $\Lambda$ and $\Lambda^{\prime}$ are the viscous and thermal characteristic lengths of the substrate. In the limp frame model, the effective density is modified to take into account the inertia added by the limp solid phase:

$$
\rho_{\text {limp }}(\omega)=\frac{\left(\rho_{s}+\phi \rho_{0}\right) \rho_{\text {rigid }}(\omega)-\rho_{0}^{2}}{\left(\rho_{s}+\phi \rho_{0}\right)+\rho_{\text {rigid }}(\omega)-2 \rho_{0}}
$$

Model parameters are evaluated for each substrate and each moisture content using an iterative optimization process which minimizes for each measurement the error between the measured absorption coefficient spectrum (Fig 9(b) or 9(c) and the calculated one with rigid-frame or limp frame model. A genetic algorithm is used on ten different starting populations in order to verify its convergence. For perlite, similar results are obtained with rigid-frame and limp frame models. Best results for coir dust are obtained with limp frame model. Final parameters are reported in table 3 for coir dust and table 4 for 
perlite. Effective density and compressibility simulated with these parameters are displayed in Fig 9 and 10 .

Variation of coir dust parameters obtained for different samples of the same substrate and same moisture content do not exceed $7 \%$ excepted for thermal length at a moisture content of $30 \%$. Calculated porosities agree with measurements made with the porosimeter excepted for a $200 \%$ moisture content. Calculated airflow resistivities are smaller than those measured with the flow resistivity meter. In particular, the increase of resistivity measured with the resistivimeter for a moisture content of $15 \%$ (table 2 and Fig $4(\mathrm{c})$ is not found. The monotoneous decrease of resistivity with moisture content above $15 \%$ is consistent with previous measurements. Calculated effective densities (Fig. 10(a) and 10(b) exhibit variations with moisture content of the same order of magnitude than the measured ones (Figs. 8(a) and 8(b). However, the fine evolution is not correctly described. Differences on real part of density for moisture contents of 15 and $30 \%$ can originate from the high sensitivity of substrate resistivity to substrate-water mixing process mentionned previously. Calculated imaginary parts of density are also very different from measured ones at moisture contents of $0 \%$ and $200 \%$. Real parts of calculated effective compressibility (Fig,10(c) are slightly overestimated and their decrease between low (0 to $30 \%)$ and high $(200 \%)$ moisture contents is correctly described.

Perlite parameters display larger variations between samples than that of coir dust in particular for airflow resistivity. Calculated porosities are much lower than measured ones with the porosimeter at any moisture content. Calculated airflow resistivities decrease with increasing moisture contents contrary to the values measured with the resistivimeter. Calculated effective densities (Fig. $12(\mathrm{a})$ and $12(\mathrm{~b})$ are the same order of magnitude than the measured ones (Figs. 8(c) and 8(d) . The largest calculated densities (real and imaginary parts) are obtained for a moisture content of $30 \%$ whereas the largest measured densities correspond to dry perlite. Calculated real parts of effective compressibility (Fig. 12(c) display similar orders of magnitude and similar decrease with moisture contents. However, the model predicts constant compressibilities value in 


\begin{tabular}{|c|c|c|c|c|c|c|}
\hline \multicolumn{2}{|c|}{$\tau$} & $\phi$ & $\sigma\left(N . s . m^{-4}\right)$ & $\alpha_{\infty}$ & $\Lambda\left(m^{-1}\right)$ & $\Lambda^{\prime}\left(m^{-1}\right)$ \\
\hline \multirow{2}{*}{0} & average & 0.62 & 1371 & 1.79 & $1.94 .10^{-4}$ & $3.35 .10^{-4}$ \\
\cline { 2 - 7 } & variation & $<0.01$ & 531 & $<0.01$ & $0.07 .10^{-4}$ & $0.15 .10^{-4}$ \\
\hline \multirow{2}{*}{0.15} & average & 0.54 & 1477 & 1.53 & $2.10 .10^{-4}$ & $3.52 .10^{-4}$ \\
\cline { 2 - 7 } & variation & 0.04 & 917 & 0.07 & $0.30 .10^{-4}$ & $0.25 .10^{-4}$ \\
\hline \multirow{2}{*}{0.30} & average & 0.28 & 2402 & 1 & $1.43 .10^{-4}$ & $3.15 .10^{-4}$ \\
\cline { 2 - 7 } & variation & $<0.01$ & 649 & $<0.01$ & $0.01 .10^{-4}$ & $0.03 .10^{-4}$ \\
\hline
\end{tabular}

Table 3: Parameters of rigid-frame Johnson-Champoux-Allard model of dry and moistened perlite substrates.

\begin{tabular}{|c|c|c|c|c|c|c|}
\hline \multicolumn{2}{|c|}{$\tau$} & $\phi$ & $\sigma$ & $\alpha_{\infty}$ & $\Lambda$ & $\Lambda^{\prime}$ \\
\hline \multirow{2}{*}{0} & average & 0.89 & 32316 & 1.02 & $1.04 .10^{-5}$ & $4.98 .10^{-5}$ \\
\cline { 2 - 7 } & variation & 0.01 & 65 & 0.01 & $0.01 .10^{-5}$ & $0.1 .10^{-5}$ \\
\hline \multirow{2}{*}{0.15} & average & 0.82 & 22273 & 1.04 & $7.98 .10^{-6}$ & $5.03 .10^{-5}$ \\
\cline { 2 - 7 } & variation & $<0.01$ & 134 & $<0.01$ & $0.15 .10^{-5}$ & $0.24 .10^{-5}$ \\
\hline \multirow{2}{*}{0.3} & average & 0.98 & 29551 & 1.03 & $1.42 .10^{-5}$ & $2.26 .10^{-4}$ \\
\cline { 2 - 7 } & variation & 0.02 & 148 & $<0.01$ & $0.05 .10^{-5}$ & $0.75 .10^{-4}$ \\
\hline \multirow{2}{*}{2} & average & 0.6 & 5730 & 1.17 & $9.26 .10^{-5}$ & $2.39 .10^{-4}$ \\
\cline { 2 - 7 } & variation & $<0.01$ & 395 & $<0.01$ & $0.19 .10^{-5}$ & $0.06 .10^{-4}$ \\
\hline
\end{tabular}

Table 4: Parameters of limp frame model of dry and moistened coir dust substrates.

the considered frequency range whereas measurements display an increase of compressibility with frequency.

\section{Effect of moisture content on the acoustic properties of green en-} velopes

To evaluate the impact of moisture content on the acoustic performance of a green envelope, simulations are conducted on a composite sample composed of a $8 \mathrm{~cm}$ thick layer of spindle (95\% porosity) atop a $8 \mathrm{~cm}$ thick layer of substrate using two methods: 1) transfer matrix method using effective properties obtained 
experimentally for dry and moistened substrates and for plants [11]; 2) transfer matrix method using porous model for substrates and effective properties obtained experimentally for plants. Variation of absorption coefficient and surface impedance with moisture contents for plant-perlite and plant-coir dust composite samples are displayed in Figs. 12 and 13 for both calculation methods. For a composite sample with dry perlite, an acoustic absorption coefficient above 0.95 is obtained between 400 and $1000 \mathrm{~Hz}$ (Fig. 12(c)). High absorption coefficient and broad band of absorption may be attributed to both quarter-wavelength thickness resonance of the envelope and the impedance matching provided by the plant layer which acts as a quarter-wavelength transformer between the air and the substrate [11. For moisture contents of 15 or $30 \%$, a slight degradation of absorption band is found with model 1 between 300 and $900 \mathrm{~Hz}$ due to the lower attenuation and the higher characteristic impedance of moistened perlite that detunes the matching effect provided by the plant layer. Slight variations of absorption coefficient are also predicted when using rigid-frame porous model 2 but with better absorption for $15 \%$ moisture content than for dry perlite. The main differences between the models are observed on surface impedance below $500 \mathrm{~Hz}$.

For a composite sample with dry coir dust, an acoustic absorption coefficient above 0.8 is obtained between 200 and $1000 \mathrm{~Hz}$ (Fig. 12(a) with both models. For moistened coir dust, the absorption coefficient calculated with model 1 is degraded between 150 and $700 \mathrm{~Hz}$ for any moisture contents. The lower speed of sound in moistened coir dust shifts down below $100 \mathrm{~Hz}$ the quarter-wavelength thickness resonance of the envelope. Therefore, an anti-resonance peak appears near $200 \mathrm{~Hz}$ and the impedance mismatch between air characteristic impedance and envelope surface impedance increases (Fig. 12(b)]. A much more limited shift of thickness resonance is obtained with limp frame porous model 2 with smaller changes in acoustic absorption for moisture contents of 15 and $30 \%$. Again, the main differences between the models concern the surface impedance below $400 \mathrm{~Hz}$. 


\section{Summary and conclusion}

Different variations of effective density and compressibility with moisture content are measured for the two considered substrates. In perlite, a sharp drop of real and imaginary parts of density and a slight decrease of real part of compressibility with some oscillations are observed in the presence of moisture. Coir dust exhibits a much more complex behaviour. Real and imaginary parts of its effective density increase at low moisture contents. At high moisture content, real part of density decreases (at a value that remains higher than the value for dry coir dust) and the imaginary part of density remains stable. For effective compressibility, real part decreases monotonously with increasing moisture content while imaginary part strongly increases for low moisture content and then decreases (at a value that remains higher than the value for dry coir dust) at high moisture content. In addition, large oscillations with frequency of real and imaginary parts of density and imaginary part of compressibility are observed in moistened coir dust. These different variations may be analyzed using complementary measurements of dry and moistened substrate porosity, density and the knowledge of perlite and coir dust particles microstructure. Perlite particles are stiff and can only trap water in their micropores. On the contrary, pithy tissue particles constituting most of coir dust substrate are soft and can store water into their cells. Therefore, coir dust particles constitute a soft frame and have a volume which tends to increase with moisture content.

Two different porous models are considered to predict properties of these lightweight substrates: rigid-frame Johnson-Champoux-Allard model for perlite and limp frame for coir dust. Estimation of model parameters is difficult in the case of perlite. Large differences are found between measured static values of porosity and airflow resistivity and values of these parameters issued from an optimization process using a measured acoustic absorption spectrum. Consequently, rigid-frame model fails to predict the variations of effective density with moisture content. For coir dust, variation of real parts of density and compressibility with moisture content is well captured by the limp frame model qualitatively. 
Some differences remains on the imaginary part of density for dry coir dust and moistened coir dust with a $200 \%$ content. In addition, the low speed of sound of the considered substrates, $40-100 \mathrm{~ms}-1$ for coir dust and $80-220 \mathrm{~ms}-1$ for perlite, questions the validity of plane-wave hypothesis used in the models. Differences between absorption coefficient of the same substrate and moisture content measured with impedance tube of different diameters could be explained by radial effects.

Finally, simulations of plant-substrate envelopes designed to have a high and broadband acoustic absorption in dry condition show that moisture tends to reduce absorption coefficient as reported in previous works [3, 5, 7, 8, 10, This degradation of absorption spectrum has different origins according to the considered substrate: a lower attenuation and a higher characteristic impedance of the substate in the case of moistened perlite; a lower speed of sound of the substrate that shifts down the first absorption peak below $100 \mathrm{~Hz}$ in the case of moistened coir dust. The considered porous models evaluate correctly the measured absorption spectrum of plant-subtrate envelopes in dry condition. However, they failed to estimate their surface impedance spectrum below 500 $\mathrm{Hz}$ and the changes of their absorption coefficient due to moisture.

\section{Acknowledgement}

This work was supported by ADEME, Yncréa Group and "Hauts-de-France" region. We also thank Geoffrey Pot and Nicolas Côté for their help in the experiments and the anonymous reviewers for their helpful and relevant comments.

\section{References}

[1] E. Oberndorfer, J. Lundholm, B. Bass, R. Coffman, H. Doshi, N. Dunnett, S. Gaffin, M. Köhler, K. Liu, B. Rowe, Green roofs as urban ecosystems: ecological structures, functions, and services, Bioscience 57 (10) (2007) 823833. 
[2] A. Niachou, K. Papakonstantinou, M. Santamouris, A. Tsangrassoulis, G. Mihalakakou, Analysis of the green roof thermal properties and investigation of its energy performance, Energy and buildings 33 (7) (2001) 719-729.

[3] T. A. Pugh, A. R. MacKenzie, J. D. Whyatt, C. N. Hewitt, Effectiveness of green infrastructure for improvement of air quality in urban street canyons, Environmental science \& technology 46 (14) (2012) 7692-7699.

[4] N. H. Wong, A. Y. K. Tan, P. Y. Tan, K. Chiang, N. C. Wong, Acoustics evaluation of vertical greenery systems for building walls, Building and Environment 45 (2) (2010) 411-420.

[5] M. Connelly, M. Hodgson, Experimental investigation of the sound absorption characteristics of vegetated roofs, Building and Environment 92 (2015) 335-346.

[6] T. Van Renterghem, D. Botteldooren, In-situ measurements of sound propagating over extensive green roofs, Building and environment 46 (3) (2011) 729-738.

[7] T. van Renterghem, D. Botteldooren, Numerical evaluation of sound propagation over green roof, Journal of Sound and Vibration 317 (2008) 781-799.

[8] T. Van Renterghem, M. Hornikx, J. Forssen, D. Botteldooren, The potential of building envelope greening to achieve quietness, Building and Environment 61 (2013) 34-44.

[9] K. V. Horoshenkov, H. Benkreira, A. Khan, The effect of moisture and soil type on the acoustic properties of green noise control elements, in: Proceedings of Forum Acusticum 2011, Aalborg, Denmark, 2011.

[10] K. V. Horoshenkov, A. Khan, H. Benkreira, Acoustic properties of low growing plants, The Journal of the Acoustical Society of America 133 (5) (2013) 2554-2565. 
[11] E. Attal, N. Côté, T. Shimizu, B. Dubus, Sound absorption by green walls at normal incidence: physical analysis and optimization, Acta Acust United Acustica 105 (2019) 301-312.

[12] H.-S. Yang, J. Kang, C. Cheal, Random-incidence absorption and scattering coefficients of vegetation, Acta Acustica united with Acustica 99 (3) (2013) 379-388.

[13] E. Attal, B. Dubus, T. Leblois, B. Cretin, An optimal dimensioning method of a green wall structure for noise pollution reduction, Building and Environment 187 (2021) 107362.

[14] C. Farrel, X. Q. Ang, J. P. Rayner, Water-retention additives incease plant available water in green roof substrates, Ecological engineering 52 (2013) $112-118$.

[15] A. J. Cramond, C. G. Don, Effects of moisture content on soil impedance, Journal of the Acoustical Society of America 82 (1987) 293-301.

[16] J. M. Sabatier, H. Hess, W. P. Arnott, K. Attenborough, M. J. M. Römkens, E. H. Grissinger, In situ measurements of soil physical properties by acoustical techniques, Soil Science Society of America Journal 54 (1990) 658-672.

[17] K. V. Horoshenkov, M. H. A. Mohamed, Experimental investigation of the effects of water saturation on the acoustic impedance of sandy soils, Journal of the Acoustical Society of America 120 (2006) 1910-1921.

[18] T. Oshima, Y. Hiraguri, T. Okuzono, Distinct effects of moisture and air contents on acoustic properties of sandy soils, Journal of the Acoustical Society of America 138 (2006) EL258-EL263.

[19] M. L. Oelze, W. O'Brien, R. G. Darmody, Measurement and attenuation of speed of sound in soils, Soil Science Society of America Journal 66 (2002) 788-796. 
[20] T. Van Renterghem, D. Botteldooren, Influence of rainfall on the noise shielding by a green roof, Building and environment 82 (2014) 1-8.

[21] C. Liu, M. Hornikx, Effect of water content on noise attenuation over vegetated roofs: Results from two field studies, Building and Environment 146 (2018) $1-11$.

[22] O. Doutres, Y. Salissou, A. Noureddine, R. Panneton, Evaluation of the acoustic and non-acoustic properties of sound absorbing materials using a three-microphone impedance tube, Applied Acoustics 71 (2010) 506-509.

[23] M. Drzal, W. Fonteno, D. Cassel, Pore fraction analysis: a new tool in substrate analysis, Acta Horticulturae 481 (1999) 43-54.

[24] M. Raviv, R. Wallach, A. Silber, A. Bar-Tal, Subtrates and their analysis, Embyo Publications, Athens, 2002, Ch. 2, pp. 25-101.

[25] M. R. Evans, S. Konduru, R. H. Stamps, Source variation in physical and chemical properties of coconut coir dust, HortScience 31 (6) (1996) 965967.

[26] M. Abad, F. Fornes, C. Carrion, V. Noguera, P. Noguera, A. Maquieira, R. Puchades, Physical properties of various coconut coir dusts compared to peat, HortScience 40 (7) (2005) 2138-2144.

[27] Y. H. Rieh, J. Kim, Changes in physical properties of various coconut coir dusts and perlite mixes and their capacitance sensor volumetric water content calibrations, HortScience 52 (1) (2017) 162-166.

[28] J. S. Fields, W. C. Fonteno, B. E. Jackson, J. L. Heitman, J. S. Owen Jr., Hydrophysical properties, moisture retention, and drainage profiles of wood and traditional components for greenhouse substrates, HortScience 49 (6) (2014) 827-832.

[29] F. Fornes, R. Belda, M. Abad, P. Noguera, R. Puchades, A. Maquieira, V. Noguera, The microstructure of coconut coir dust for use as alterna- 
tives to peat in soilless growing media, Australian Journal of Experimental Agriculture 43 (2003) 1171-1179.

[30] P. Noguera, M. Abad, R. Puchades, A. Maquieira, V. Noguera, Influence of particle size on physical and chemical properties of coconut coir dust as container medium, Communications in Soil Science and Plant Analysis 34 (3-4) (2003) 593-605.

[31] M. Dogan, M. Alkan, Some physiochemical properties of perlite as an adsorbent, Fresenius Environmental Bulletin 13 (3b) (2004) 251-257.

[32] S. Kaufhold, A. Reese, W. Schwiebacher, R. Dohrmann, G. Grathoff, L. Warr, M. Halisch, C. Müller, U. Schwarz-Schampera, K. Ufer, Porosity and distribution of water in perlite from the island of milos, greece, SpringerPlus 3 (2014) 598-607.

[33] S. Bures, O. Marfa, F. X. Martinez, Water characterization in granular materials (refereed), Acta Horticulturae 450 (1997) 389-396.

[34] D. L. Johnson, J. Koplik, R. Dashen, Theory of dynamic permeability and tortuosity in fluid-saturated porous media, Journal of Fluid Mechanics 176 (1987) 379-402.

[35] Y. Champoux, J.-F. Allard, Dynamic tortuosity and bulk modulus in airsaturated porous media, Journal of Applied Physics 70 (1991) 1975-1979.

[36] R. Panneton, Comments on the limp frame equivalent fluid model for porous media, The Journal of the Acoustical Society of America 122 (6) (2007) EL217-EL222.

[37] ISO, 10534-2: Determination of sound absorption coefficient and impedance in impedance tubes, part 2: Transfer-function method, in: ISO, International Organization for Standardization, 1998, pp. 1-12.

[38] T. E. Vigran, L. Kelders, W. Lauriks, P. Leclaire, T. Johansen, Prediction and measurements of the influence of boundary conditions in a standing wave tube, Acta Acustica United with Acustica 83 (3) (1997) 419-423. 


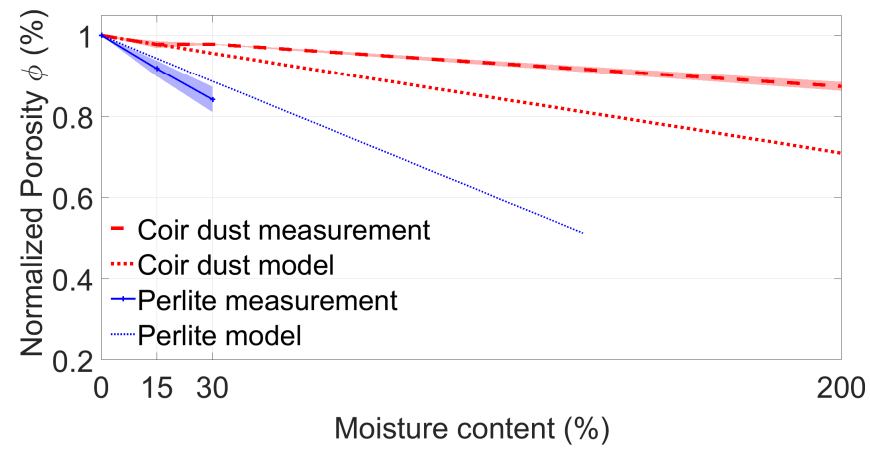

(a)

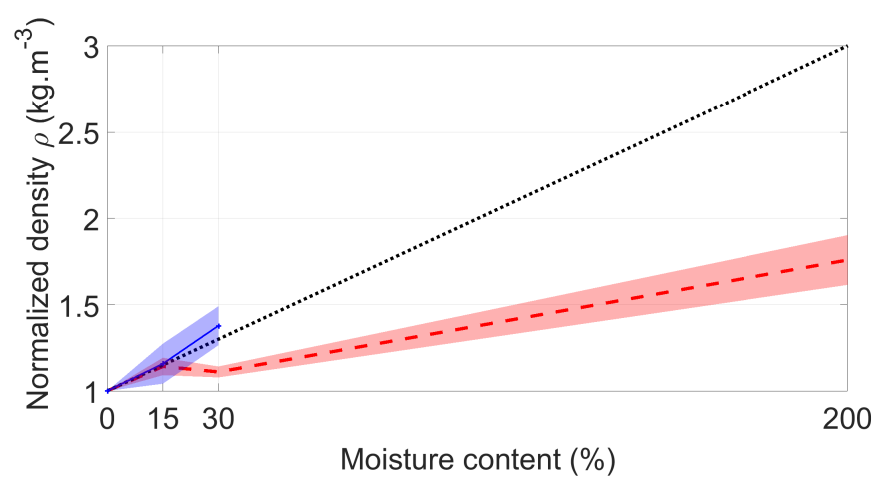

(b)

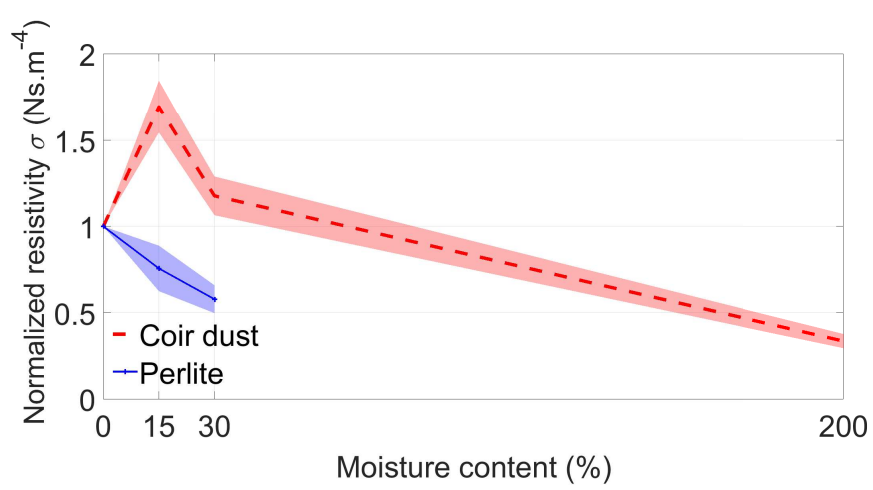

(c)

Figure 4: Variation of coir dust and perlite physical parameter with moisture content: (a) normalized porosity, (b) normalized density, (c) normalized airflow resistivity 


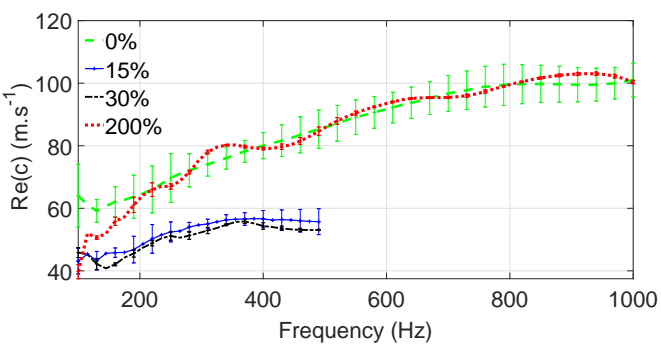

(a)

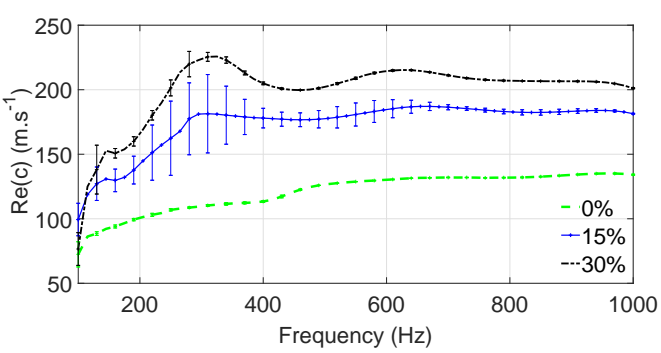

(c)

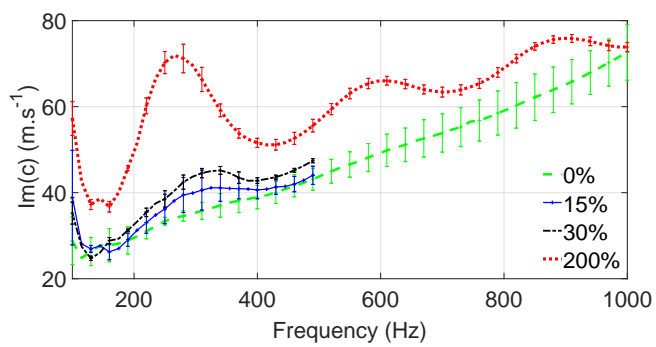

(b)

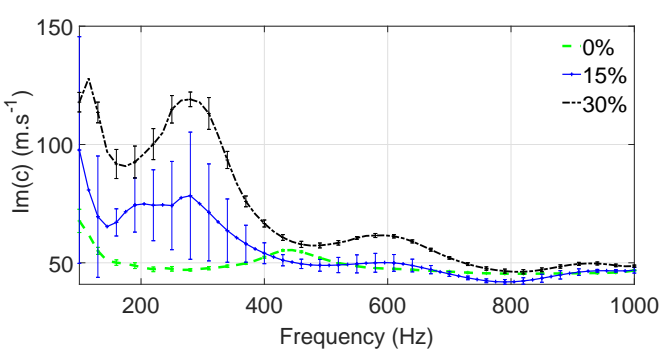

(d)

Figure 5: Measured real and imaginary parts of effective speed of sound of substrates for moisture contents varying between 0 and $30 \%$ or $200 \%$. Coir dust: (a) and (b) and Perlite (c) and (d). Full line: average value; error bars: standard deviation. 


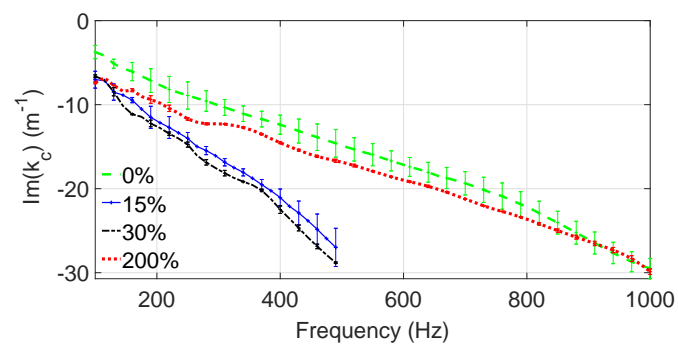

(a)

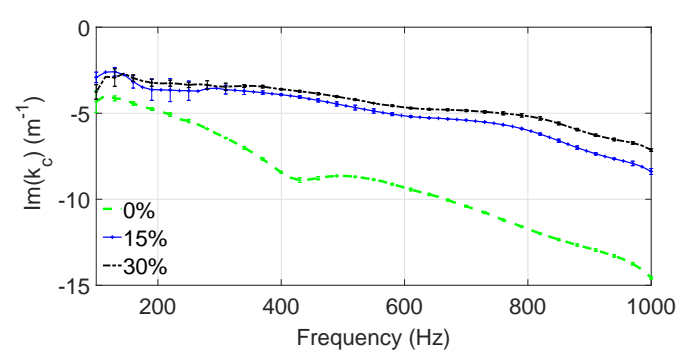

(c)

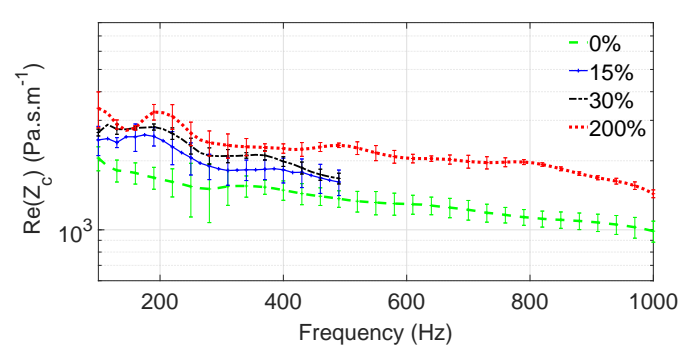

(b)

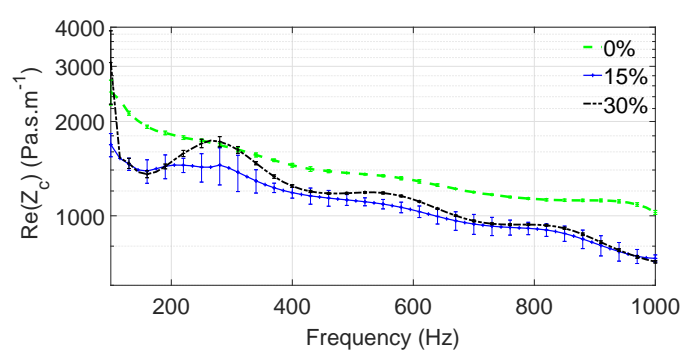

(d)

Figure 6: Measured effective attenuation and real part of characteristic impedance of substrates for moisture contents varying between 0 and $30 \%$ or $200 \%$. Coir dust : (a) and (b). Perlite: (c) and (d). Full line: average value; error bars: standard deviation. 


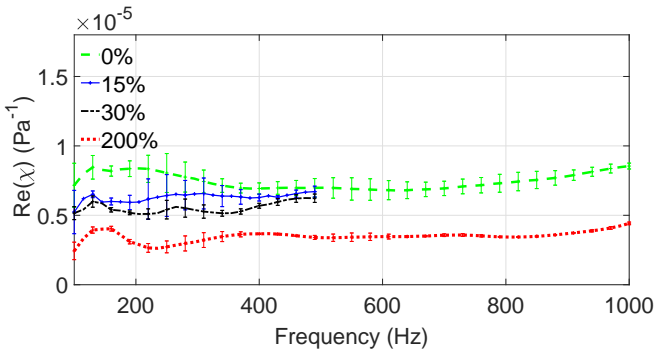

(a)

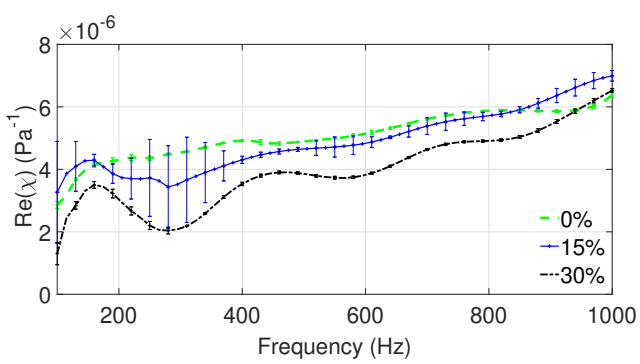

(c)

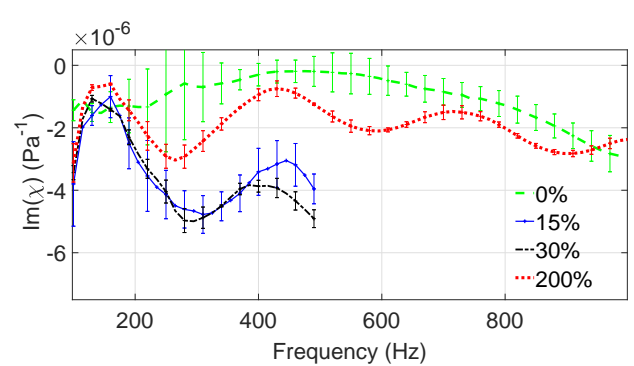

(b)

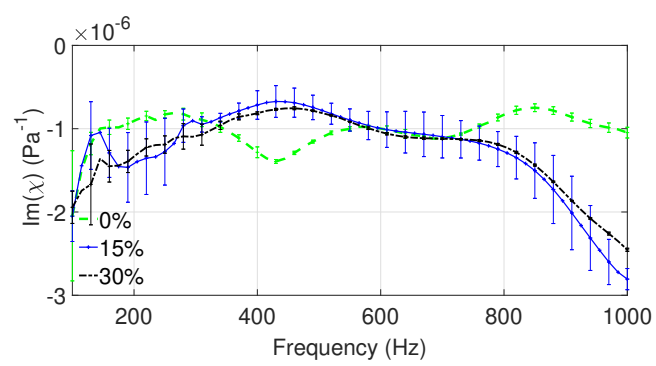

(d)

Figure 7: Measured effective real and imaginary parts of substrates compressibility for moisture contents varying between 0 and $30 \%$ or $200 \%$. Coir dust: (a) and (b). Perlite: (c) and (d). Full line: average value; error bars: standard deviation. 


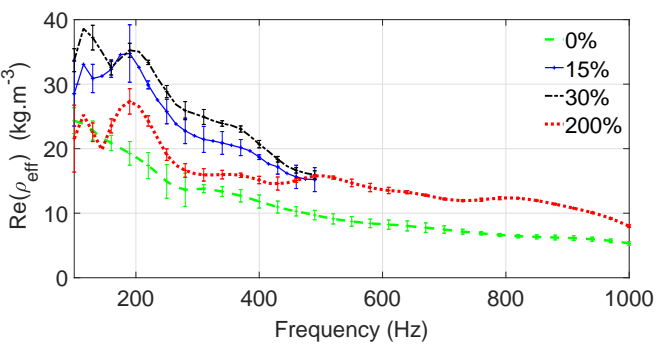

(a)

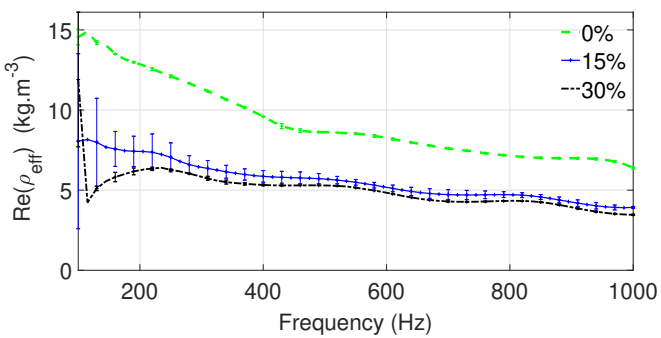

(c)

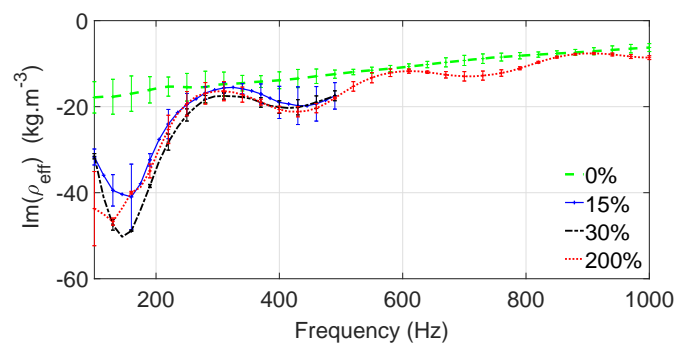

(b)

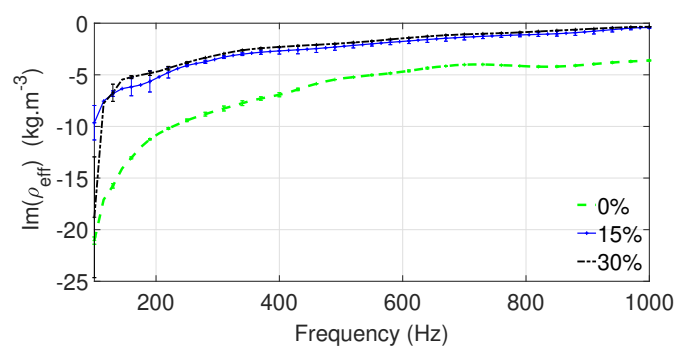

(d)

Figure 8: Measured effective real and imaginary parts of substrates density for moisture contents varying between 0 and $30 \%$ or $200 \%$. Coir dust: (a) and (b).Perlite: (c) and (d). Full line: average value; error bars: standard deviation. 


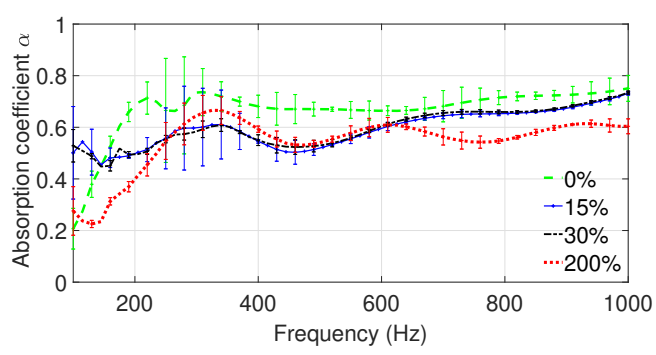

(a)

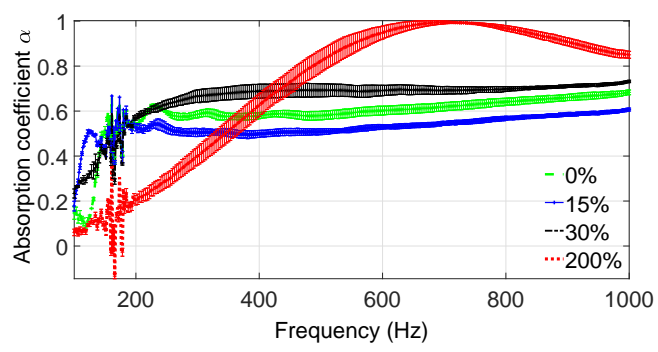

(c)

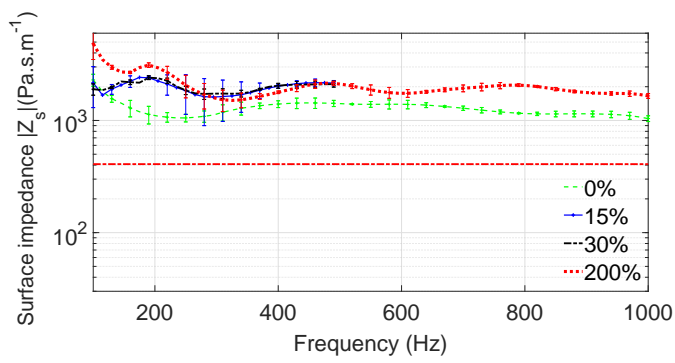

(e)

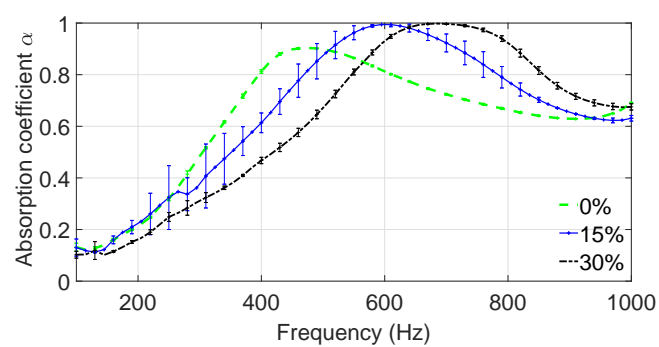

(b)

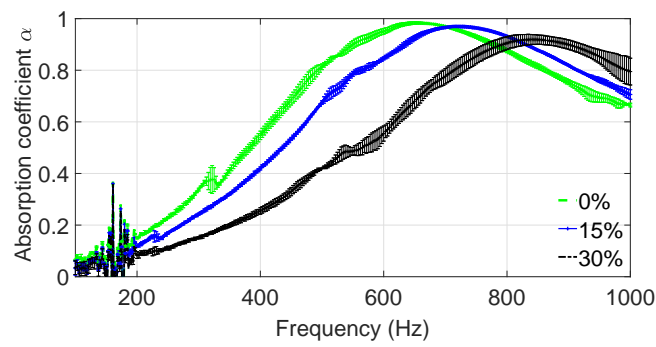

(d)

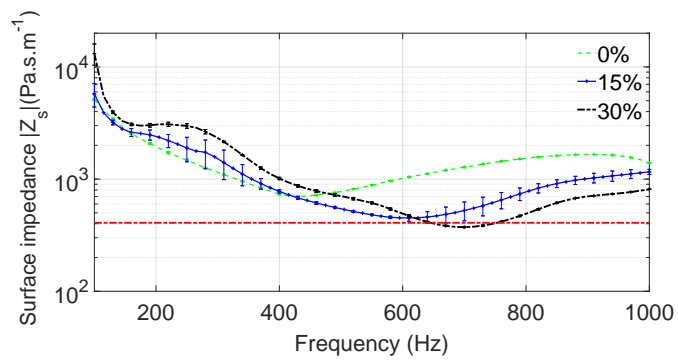

(f)

Figure 9: Measured absorption coefficients and surface impedance of $8 \mathrm{~cm}$ thick substrate samples for different moisture contents. Absorption coefficient measured with first method : (a) coir dust, (b) perlite. Absorption coefficient measured with second method : (c) coir dust, (d) perlite. Surface impedance measured with first method : (c) coir dust, (f) perlite. Full line: average value; error bars: standard deviation 


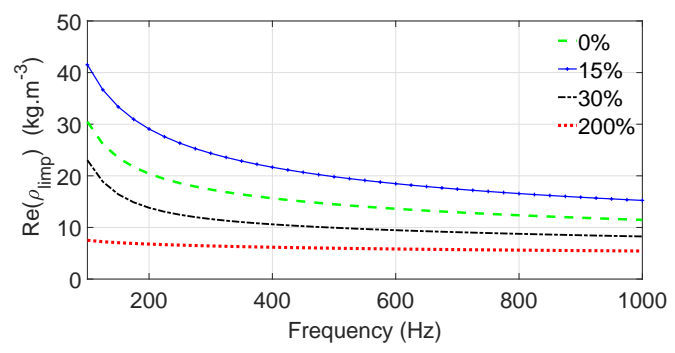

(a)

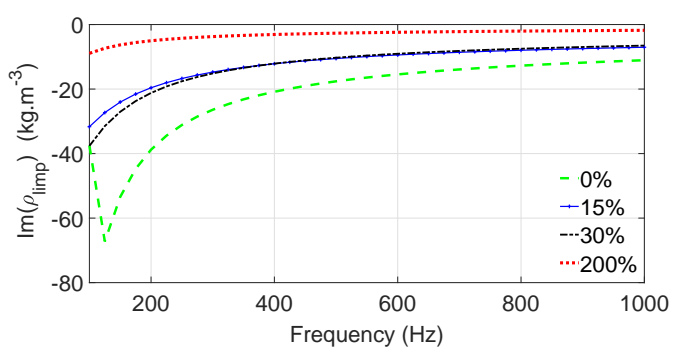

(b)

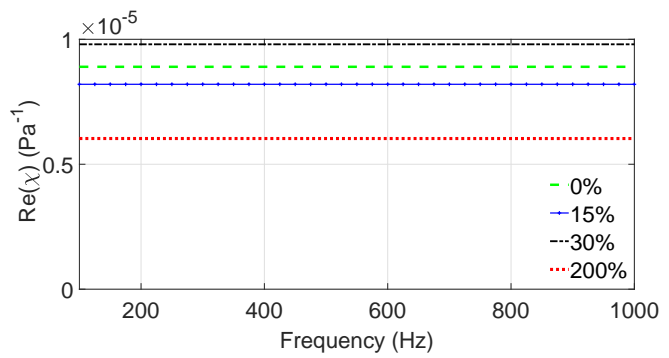

(c)

Figure 10: Effective density and compressibility of dry and moistened coir dust calculated using limp frame model. Density: real part (a); imaginary part (b). Compressibility: real part (c); imaginary part negligible (not drawn). 


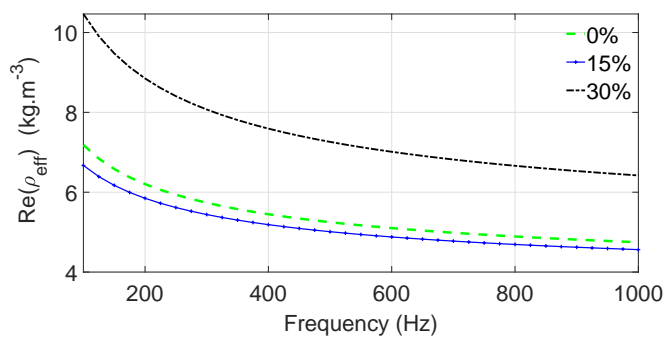

(a)

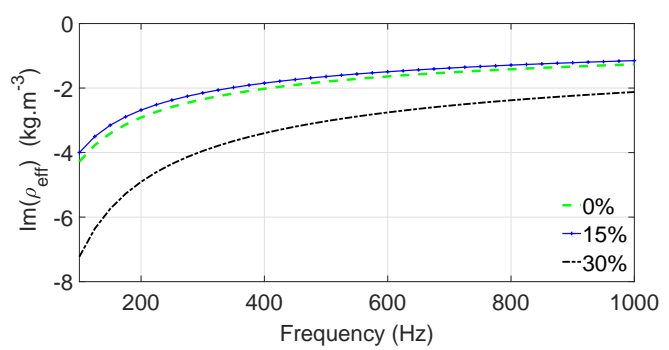

(b)

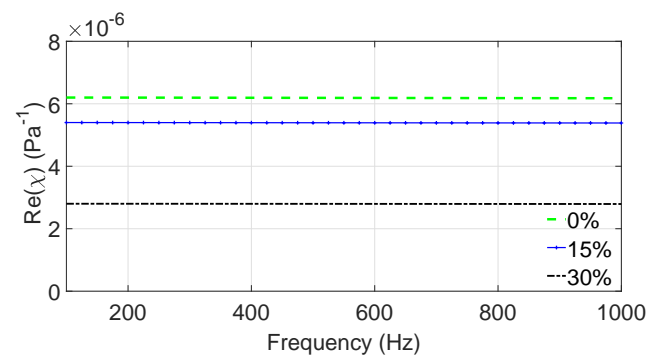

(c)

Figure 11: Effective density and compressibility of dry and moistened perlite calculated using rigid-frame model. Density: real part (a); imaginary part (b). Compressibility: real part (c); imaginary part negligible (not drawn). 


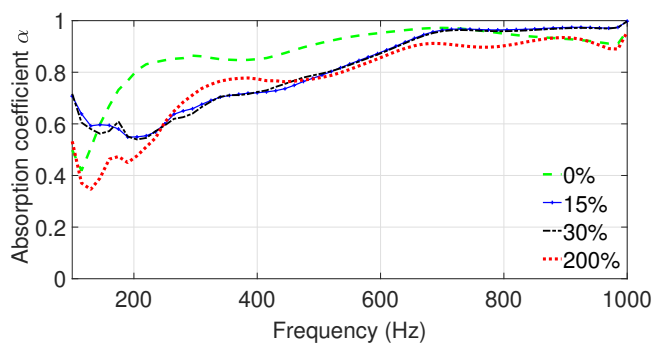

(a)

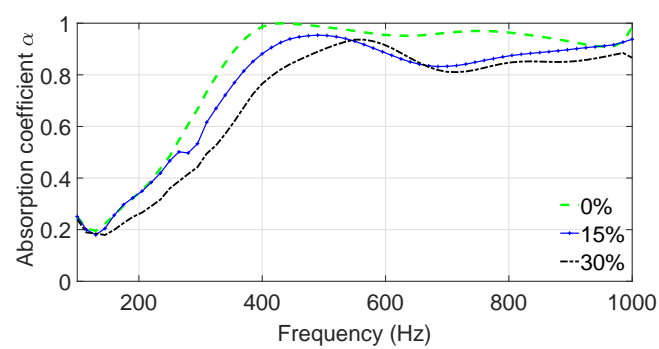

(c)

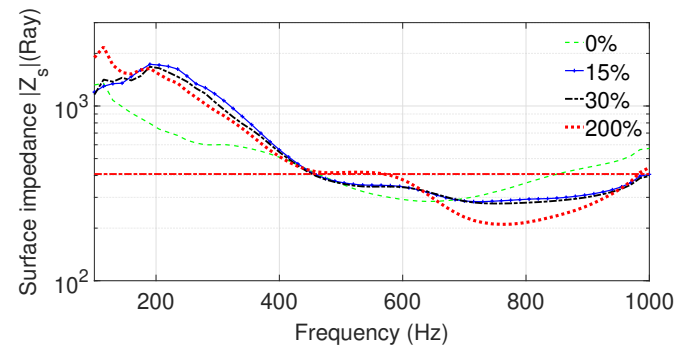

(b)

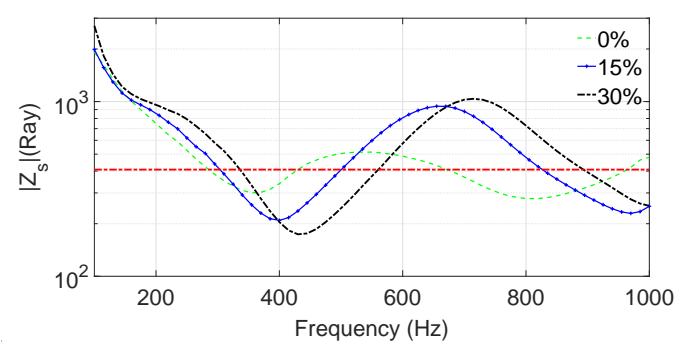

(d)

Figure 12: Absorption coefficient and surface impedance of composite samples $(8 \mathrm{~cm}$ thick plant atop $8 \mathrm{~cm}$ thick substrate) calculated with method 1 for different moisture contents . Coir dust: (a) and (b). Perlite: (c) and (d). 


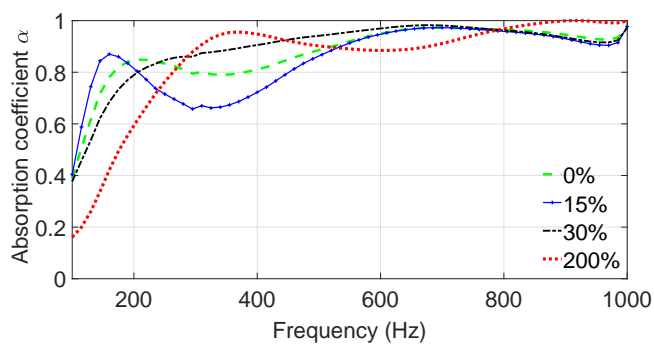

(a)

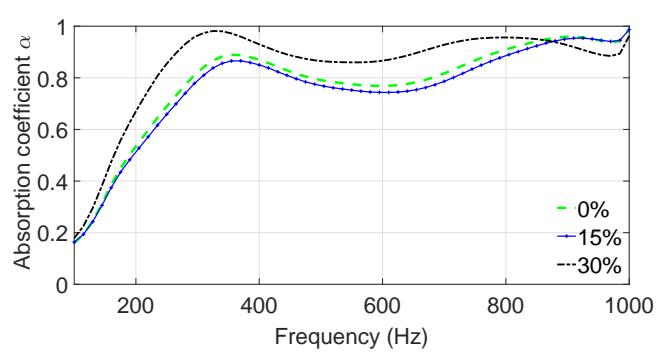

(c)

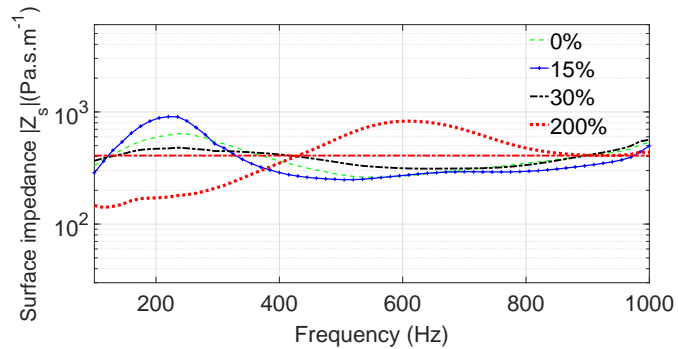

(b)

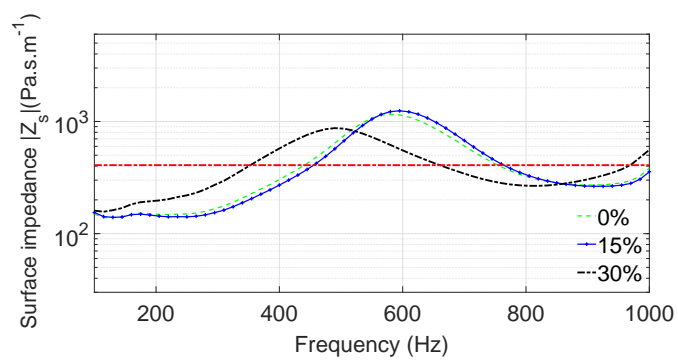

(d)

Figure 13: Absorption coefficient and surface impedance of composite samples $(8 \mathrm{~cm}$ thick plant atop $8 \mathrm{~cm}$ thick substrate) calculated with method 2 for different moisture contents. Coir dust: (a) and (b). Perlite: (c) and (d). 